\title{
Pecado, crime e patologia: produções discursivas acerca da perversão*1
}

\section{Sin, crime and pathology: discursive productions on perversion}

André Luiz Alexandre do Vale*2

Marta Rezende Cardoso*3

\begin{abstract}
Baseando-nos nas análises genealógica e epistemológica propostas por Foucault e Lantéri-Laura, nosso objetivo principal é discernir quais são as principais linhas discursivas que constituiram o saber em torno da perversão, produzindo um sujeito dito perverso. Emerge de maneira fundamental dessa leitura como a ideia de transgressão de limites acompanha a história dos perversos: seja o limite moral imposto pela autoridade divina, seja o limite jurídico determinado pela lei penal, seja o limite do normal definido pela medicina, a perversão sempre aponta para o excesso transgressor. Tais leituras constituem o solo epistemológico sobre o qual Freud se apoia na concepção de uma metapsicologia cujo eixo central é a sexualidade. $O$ discurso freudiano subverte o estatuto da perversão ao afirmá-la como dimensão inescapável da sexualidade e da constituição da subjetividade humana.
\end{abstract}

Palavras-chave: Perversão, sexualidade, transgressão, psicanálise

*1 $\mathrm{O}$ artigo foi baseado na tese "As bases narcísicas da perversão: onipotência e recusa da alteridade" (2018), apresentada ao Programa Pós-Graduação em Teoria Psicanalítica, Instituto de Psicologia, Universidade Federal do Rio de Janeiro - UFRJ.

*2, ${ }^{3}$ Universidade Federal do Rio de Janeiro - UFRJ (Rio de Janeiro, RJ, Brasil). 
Ao pensarmos nas perversões, somos muito facilmente levados a imaginar um conjunto de práticas aberrantes no campo sexual, marcadas pela degradação de uma série de preceitos morais que sustentam o tecido social. Tais depravações seriam cometidas por uma pequena parcela de indivíduos supostamente degenerados e avessos aos interditos de gozo, estando delas isento o restante da "boa humanidade". Consideradas por este viés, as perversões não seriam nada além de uma anomalia das práticas sexuais, alcançando o estatuto de patologia em suas formas mais violentas (Birman, 1999).

Os estudos da etnologia mostram desde há muito que, ao longo de toda a história das culturas humanas, sempre houve uma divisão muito marcada entre o permitido e o ilícito no campo das práticas sexuais, invariante que pode ser considerada uma constante antropológica: nenhuma sociedade aceita todas as formas possíveis de gozo, tampouco as exclui, autorizando ou proibindo pelo menos uma. Entretanto, como indicam, por exemplo, Lantéri-Laura (1979/1994) e Pirlot e Pedinielli (2013), esses estudos mostram também a relatividade dos interditos sexuais, de modo que o que é definido como lícito e ilícito é extremamente variável de uma cultura para outra, e o que provoca horror e punições severas em uma, nada mais é que uma amena fantasia em outra.

Da mesma forma que a divisão entre o lícito e o ilícito é uma constante antropológica, a presença daqueles que transgridem os interditos sexuais também o é. A figura do perverso assumiu diversos atributos ao longo de sua história transgressiva, evidenciando como os qualificativos a essas transgressões são também bastante variáveis de uma época para outra. Se contemporaneamente é o discurso médico-psiquiátrico que dela se ocupa, nem sempre foi assim. De fato, a apropriação médica das perversões só veio muito tardiamente no século XIX, e antes disso o campo estava sob domínio das religiões e do Direito, sobretudo penal. 
Seja como pecado, no discurso moral-religioso, como crime, no discurso jurídico-penal, ou como patologia, no discurso médico-científico, a perversão sempre foi marcada pela ideia de "desvio" em relação a uma suposta norma. Baseando-nos, sobretudo, nas análises genealógica proposta por Foucault (1976/1988) e epistemológica proposta por Lantéri-Laura (1979/1994) acerca da perversão, nosso objetivo principal é discernir quais são as principais linhas discursivas que constituíram o saber em torno da perversão, produzindo um sujeito dito perverso. Em decorrência disso, podemos reconhecer o solo epistemológico sobre o qual Freud se apoia na constituição de uma metapsicologia cujo eixo central é a sexualidade - suas fixações e regressões, transgressões e limites. A subversão freudiana está subsidiada pelo entendimento de que a perversão não faz parte apenas de uma bizarrice no campo das práticas sexuais, mas é dimensão inescapável da própria sexualidade.

\section{O discurso transgressivo da psicanálise}

Desde seu nascimento, a psicanálise redefiniu completamente a sexualidade, desvinculando-a da sua limitação à heterossexualidade com objetivos reprodutivos, o que provocou significativo abalo à estrutura moral vigente de sua época. Se até então o discurso médico-científico, por mais que se pretendesse neutro e asséptico, mantinha suas raízes na moral judaico-cristã, a "descoberta" freudiana vem revolucionar a compreensão da subjetividade humana, cuja constituição psíquica não pode ser separada da sexualidade.

O discurso psicanalítico a respeito das perversões nasce "apoiado" no discurso médico-psiquiátrico do início do século XX - para então ser "pervertido". Na subversiva obra publicada em 1905 e reiteradamente editada nos anos que se seguiram (1910, 1915, 1920 e 1924), "Três ensaios sobre a teoria da sexualidade", Freud (1905/1996c) inicia sua argumentação analisando as "aberrações sexuais" a partir dos grandes compêndios de transtornos psiquiátricos, amplamente difundidos no meio científico de sua época. Suas proposições revolucionárias vieram desconstruir a concepção de sexualidade que dava sustentação a esses compêndios. A revolução provocada pelo discurso psicanalítico deve-se à descoberta freudiana de que a sexualidade humana seria essencialmente perverso-polimorfa, de tal forma que a oposição dicotômica entre aquilo que seria dito normal e o perverso sofre profundo abalo em sua estrutura.

Ao olharmos para a obra freudiana através da lente da perversão, evidencia-se como ela está presente, sendo mesmo determinante, em importantes momentos: seja 


\section{HISTÓRIA DA PSICANÁLISE}

no fundamento da teoria da sedução (Freud, 1896/1996a); na postulação do inconsciente como produto do recalque vindo conter desejos sexuais infantis (Freud, 1900/1996b); no contraponto feito com a neurose, como seu negativo, que levou à alteração do estatuto da fantasia e a sua importância na constituição do desejo e do conflito edípico (Freud, 1905/1996c); na introdução do conceito de narcisismo como "amor de si mesmo" e na reviravolta teórica dele decorrente (Freud, 1914/1996d); na discussão a respeito das tendências destrutivas do mal-estar e de sua regulação para a vida em sociedade (Freud, 1930[1929]/1996e); na articulação clínica com a psicose, com a qual divide mecanismos defensivos específicos (Freud, 1940[1938]/1996f)... Estes são apenas alguns exemplos de como a problemática da perversão está no âmago da construção e evolução da teoria e da clínica psicanalítica.

É no fundamental campo da sexualidade que a perversão assume lugar central, estando organicamente implicada na construção de um dos pilares da teoria psicanalítica: o conceito de pulsão. Ao postular em 1905 uma primeira teoria pulsional, baseada no conflito entre as pulsões de autoconservação, por um lado, e as pulsões sexuais, por outro, que animariam o aparelho psíquico a partir de sua dinâmica dual, Freud está propondo uma nova ontologia no cenário em que se encontrava, dando continuidade ao projeto iniciado em 1900. De modo radicalmente revolucionário, ele começa a construir uma teoria que apresenta um novo modo de pensar o ser humano, cujos pilares se encontram no inconsciente e na pulsão, conceitos embasados por esse novo olhar sobre o sexual, assentado precisamente em sua dimensão perverso-polimorfa.

Ao desconstruir uma série de preceitos consolidados em relação à sexualidade - seja através da importância concedida à fantasia em relação à factualidade; seja através da postulação de um sistema inconsciente que desconhece valores morais e cujos impulsos e desejos são alheios às barreiras para sua satisfação; seja através da definição da pulsão sexual como contingente, anárquica, plural e parcial; seja através da definição de uma dimensão "perversamente polimorfa" como algo que faz parte do processo normal da organização da sexualidade infantil — o discurso psicanalítico fez com que Freud fosse considerado por seus pares persona non grata, uma figura imoral, obscena e impopular (Santos \& Ceccarelli, 2010; Gratton, 2016). Como sustenta a subversão freudiana, a perversão é dimensão inescapável da própria sexualidade. A dimensão perversa evidencia que é a singularidade de uma história - em suas fixações e regressões, transgressões e limites —, e não uma suposta natureza, que a conforma. Vejamos alguns dos 
elementos fundamentais envolvidos na genealogia da visão de Freud acerca da perversão, em que promove a referida subversão.

\section{A desvirtuação do pensamento e do desejo}

Logo após publicar o primeiro volume de sua trilogia sobre a história da sexualidade, Foucault (1979/2010) afirma que o problema que persegue em sua argumentação gira em torno do que teria ocorrido no Ocidente, fazendo com que a questão da verdade viesse a ser relacionada ao prazer sexual. $\mathrm{O}$ autor investiga como o "dispositivo da sexualidade" deu forma a um objeto específico de saber, produzido nos discursos com estatuto e função de verdade, os quais, sob a perspectiva genealógica da análise que propõe, se ancoravam num referencial religioso-moral, depois jurídico-penal e, enfim, médico-científico.

A criação de um dispositivo de sexualidade tinha como função demarcar um conjunto verdadeiramente heterogêneo, que englobasse discursos, instituições, organizações arquitetônicas, decisões regulamentares, leis, medidas administrativas, enunciados científicos, proposições filosóficas e morais, tendo como foco a rede de articulações estabelecida entre tais elementos. Em suma, o referido dispositivo diz respeito às relações de poder que sustentam determinados tipos de saber e são, correlativamente, sustentadas por eles.

A trilogia foucaultiana acerca da história da sexualidade discorre sobre as diferentes formas segundo as quais o objeto "sexualidade" e o objeto "sexo" vieram a ser inscritos no registro da verdade, a partir de uma rede trançada por um conjunto de práticas, discursos e técnicas de estimulação dos corpos, intensificação dos prazeres e formação de conhecimentos. A construção do sexo como objeto de verdade é o aspecto central para a análise feita por Foucault, que compreende não somente a cartografia de diferentes discursos que produziram verdades sobre o sexo, mas também como, por meio desses discursos, foi possível constituir uma verdade sobre o sujeito pela via da sexualidade (Cirino, 2007; Benevides, 2013).

Inicialmente, Foucault (1976/1988) se preocupa em desconstruir o que chamou de "hipótese repressiva", segundo a qual estaríamos sujeitos até hoje a um regime vitoriano da sexualidade, caracterizado pela predominância de um tríplice decreto de interdição, inexistência e mutismo da pudicícia burguesa. De acordo com a hipótese repressiva, as práticas sexuais do século XVII teriam sido cuidadosamente encerradas no seio da família nuclear burguesa vitoriana, responsável por “calar” o sexo: “O casal, legítimo 


\section{HISTÓRIA DA PSICANÁLISE}

e procriador, dita a lei. Impõe-se como modelo, faz reinar a norma, detém a verdade, guarda o direito de falar, reservando-se o princípio do segredo" (Foucault, 1976/1988, p. 9).

No entanto, propõe o autor uma série de dúvidas consideráveis acerca desse movimento de confinamento e silêncio da sexualidade cujo objetivo é recolocar a hipótese repressiva em uma economia geral dos discursos sobre o sexo, levando em conta seus efeitos de positividade no seio das sociedades modernas a partir do século XVII. Não se trata de estabelecer contra-hipóteses que afirmariam ter sido o sexo objeto de uma liberdade constante nas sociedades capitalistas e burguesas, nas quais as estratégias do poder seriam mais tolerantes que repressivas. A proposta de Foucault é perscrutar o que, quem e como se falou da sexualidade, bem como os efeitos e as relações desses discursos com o regime de poder-saber-prazer que sustentam - em suma, trata-se de colocar o sexo em discurso, revelar a "vontade de saber" que lhe serve de suporte e instrumento.

[...] gostaria de desvincular a análise dos privilégios que se atribuem normalmente à economia de escassez e aos princípios de rarefação, para, ao contrário, buscar as instâncias de produção discursiva (que, evidentemente, também organizam silêncios), de produção de poder (que algumas vezes têm a função de interditar), das produções de saber (as quais, frequentemente, fazem circular erros ou desconhecimentos sistemáticos); gostaria de fazer a história dessas instâncias e de suas transformações. (Foucault, 1976/1988, p. 19)

No que concerne ao primeiro questionamento acerca da "hipótese repressiva", Foucault sustenta que, em vez de uma censura que haveria silenciado a sexualidade nos últimos séculos, o que se depreende é uma verdadeira explosão discursiva em torno e a propósito do sexo a partir do século XVIII. No entanto, deixa claro que não se tratou de um "tudo" falar, mas de uma política de controle dos enunciados, comportando definições estritas de onde, quando e com quem se poderia (ou não) falar dele. De fato, tratou-se de colocar o sexo em um discurso regulado.

Essa regulação tomou forma no interior de diversas instituições que se ocuparam progressivamente da sexualidade e do sexo. Em primeiro lugar, é analisada a evolução da pastoral católica e do sacramento da confissão. Até a metade do século XVI, a Igreja controlou a sexualidade de forma bastante frouxa, e somente após o Concílio de Trento - em um período em que a Igreja Católica Romana buscava assegurar a unidade da fé diante de uma Reforma Protestante que dividia a Europa e destronava sua soberania ideológica -, atribuiu-se cada vez mais importância às transgressões da moral católica. 
Segundo Pirlot e Pedinielli (2013), o discurso moral da religião é o primeiro a condenar os vícios - alguns dos quais se tornarão parte fundamental do que será ulteriormente designado como "perversão". Roudinesco (2007/2008) sublinha que a perversão era vista no seio da Idade Média como "uma forma particular de abalar a ordem natural do mundo e converter os homens ao vício" (p. 10). Essa concepção de perversão pressupunha a existência de uma autoridade divina, a qual poderia vir a ser desvirtuada e corrompida por aquele que a desafiava. "Demoníaco, amaldiçoado, criminoso, devasso, torturador, lascivo, fraudador, charlatão, delituoso, o pervertedor era em primeiro lugar uma criatura dúbia, atormentada pela figura do Diabo" ( $\mathrm{p}$. 10). O que vemos delinear-se na história das sociedades ocidentais é como, ao perverso, coube certo lugar de inumanidade, posto que sua figura representava o que de mais abjeto, maldito e bestial poderia existir no campo das práticas sexuais, julgado como extrínseco à própria natureza humana.

No que concerne ao sistema de crenças católicas, as normas que diferenciariam os puros dos ímpios foram estabelecidas desde o Antigo Testamento, no "Levítico", em que vários comportamentos sexuais são explicitamente condenados, tais como o incesto, o adultério e a sodomia. Coube à filosofia catequética de Santo Agostinho - um dos grandes difusores da doutrina católica na Idade Média, cujos textos sobre a temperança e o casamento determinam ainda hoje os limites dos interditos e dos deveres conjugais - , apregoar tais normas e, por conseguinte, as correspondentes transgressões que geravam os vícios.

Em A cidade de Deus (1989/2012) — obra publicada originalmente no início do século V - Santo Agostinho fez a primeira teologia e filosofia da história ao propor uma interpretação do mundo à luz da fé cristã. Ele propõe uma leitura de toda a existência dos homens segundo a fé, a qual é orientada para a salvação. Para que se possa alcançá-la, o cristão precisaria ultrapassar suas satisfações terrenas e seus prazeres corporais, abrindo mão da voluptuosidade provocada pela libido. A voluptuosidade deveria ser evitada, uma vez que, quando esta chega ao cúmulo, "se ofusca por completo a razão e surge a treva do pensamento" (p. 188).

O que Santo Agostinho (1989/2012) salienta é que, não somente o corpo é devassado pela libido, pelo "amor perverso", mas também a alma fica corrompida, afastando os cristãos das graças de Deus: "a luxúria não é vício da beleza e graça do corpo, mas da alma, que ama perversamente os prazeres corporais, desprezando a temperança, que nos une a coisas espiritualmente mais belas e incorruptivelmente mais cheias de graça" (p. 87). 
A preconização do casamento na filosofia teológica agostiniana desempenhou papel fundamental na evolução da pastoral católica durante a Idade Média, a qual deu imenso peso à circunscrição do sexo e da sexualidade ao matrimônio, orientados para a reprodução. $\mathrm{O}$ amor conjugal do homem e da mulher foi colocado sob o duplo preceito moral da fidelidade e da fecundidade. O matrimônio é destarte indissolúvel, não podendo ser revogado por nenhum poder humano, nem por nenhuma causa, além da morte, e deve ter como função a multiplicação da espécie.

Nesse contexto, a castidade - definida como a "virtude moral que regula retamente toda a expressão voluntária de prazer sexual dentro do casamento e a exclui totalmente fora do estado matrimonial" (Trese, 1999, p. 236) - assume papel determinante na regulação dos atos. Entretanto, a tradição católica não se restringe aos atos físicos, mas também exerce seu controle sobre as formas veementes de desejo humano, contrárias aos ditames da razão. Para evitar o desejo, é preciso manter a pureza do corpo e do espírito através da oração, do pudor corporal e dos sentimentos, da pureza de intenção e do olhar, da disciplina dos sentidos, pensamentos e da imaginação, rejeitando-se "vontades pervertidas". Muito mais do que uma regulação dos atos que tentariam a virtude da castidade, o discurso religioso-moral reitera que é pecado não somente realizar um ato sexual ilícito, mas alimentar pensamentos ou desejos com relação a outras pessoas, de modo que a regulação incide não somente no corpo, mas na esfera anímica.

Mostra Lantéri-Laura (1979/1994) que, a partir do Concílio de Trento, a castidade representava um ideal da vida cristã diante da qual o corpo, como meio de prazer, achava-se no registro do pecado, na vertente do mal, sendo a carne um lugar de impiedade. Diante disso, a única justificação para a sexualidade era a reprodução da espécie, e apenas se somada ao sacramento do matrimônio; todas as práticas que estivessem além dessa eram ilícitas, pecaminosas, em suma, perversas. Insidiosamente, essas regras foram se transformando no imperativo da moral sexual burguesa.

Neste contexto, o sexo acabou por ocupar paulatinamente o lugar de operador do controle sobre os fiéis através dos mecanismos da confissão, de modo que "pensamentos, desejos, imaginações voluptuosas, deleites, movimentos simultâneos da alma e do corpo, tudo isso deve entrar, agora, e em detalhe, no jogo da confissão e da direção espiritual" (Foucault, 1976/1988, p. 25). Opera-se, progressivamente, um deslocamento do pecado da carne para a inquietação do desejo, para os desvios nas faculdades da alma. 
Foucault (1976/1988) chama atenção para a conjuntura de que esta é a primeira vez na história do Ocidente moderno em que uma constrição geral de confessar tudo o que se relaciona ao jogo dos prazeres, sensações e pensamentos referidos ao sexo se impõe de forma tão evidente e generalizada. Não se trata apenas de confessar os atos contrários à lei religiosa, mas inserir o próprio desejo transgressivo no discurso confessional. Com isso, a intenção da pastoral cristã, que estaria por trás de tal detalhamento discursivo do campo do desejo, era produzir efeitos de domínio, mas também de reconversão espiritual, de retorno a Deus, e, portanto, de reconfiguração do próprio desejo.

Cabe pontuar que a técnica da confissão não ficou restrita à esfera religiosa, mas ampliou-se para outros mecanismos de poder, para cujo funcionamento o discurso sobre o sexo passou a ser essencial, passando a provocar uma espécie de "erotismo discursivo generalizado". A hipótese defendida por Foucault é que, em vez de sofrer um processo de restrição, a sexualidade foi submetida a um mecanismo crescente de incitação discursiva e que, a partir do fim do século XVI, a "vontade de saber" em torno da sexualidade fez com que esta fosse progressivamente deixando de ser algo 690 que se deve condenar, tolerar ou julgar, passando a ser algo a regular, gerir, administrar.

Tal incitação discursiva em torno da sexualidade não é, contudo, um fenômeno simplesmente quantitativo, mas implicou, essencialmente, uma dispersão de sexualidades, uma implantação múltipla de heterogeneidades sexuais e um reforço de suas formas absurdas, no que Foucault chamou de "implantação perversa". Sustenta ele que, desde o fim do século XVI até o fim do século XVIII, havia três grandes códigos normativos que regulavam as práticas sexuais, todos centrados nas relações matrimoniais: o direito canônico, a pastoral cristã e a lei civil, os quais fixavam, a partir de seus princípios próprios, a linha divisória entre o lícito e o ilícito. No entanto, todos se centravam no dever conjugal, no sexo dos cônjuges, configurando aquilo que ele denominou de "dispositivo da aliança".

Esse dispositivo legitimava a monogamia heterossexual, submissa à economia estrita da reprodução, e em torno da qual gravitavam "sexualidades periféricas", que seriam "contra a natureza" - e é justamente sobre essas que o foco do discurso passa a estabelecer-se: "o que se interroga é a sexualidade das crianças, a dos loucos e dos criminosos; é o prazer dos que não amam o outro sexo; os devaneios, as obsessões, as pequenas manias ou as grandes raivas" (Foucault, 1976/1988, p. 46). Ganha destaque assim a personagem 


\section{HISTÓRIA DA PSICANÁLISE}

que representa a maior transgressão às regras da aliança: o perverso. Este é "transpassado, independentemente de si mesmo, pela tenebrosa folia do sexo. [...] Deliberadamente fere a lei, ao mesmo tempo em que algo como uma natureza desviada arrebata-o para longe de qualquer natureza" (1976/1988, pp. 46-7).

O interesse em torno das "sexualidades periféricas" - tendo na figura do perverso seu protagonista - indica uma preocupação de se exercer um controle mais direto sobre elas. Entretanto, tal controle muda de feitor: se até o fim do século XVIII a igreja era a grande interventora na sexualidade conjugal, a partir do século XIX foi a medicina que empreendeu a gestão dos prazeres do casal, mas não somente ela. Seu domínio difundiu-se e espalhou-se pelos interstícios das práticas sexuais como um todo - desde a masturbação das crianças, passando pela homossexualidade e, evidentemente, pelas perversões.

Contudo, essa passagem não se deu de imediato. De fato, como esclarece Lantéri-Laura (1979/1994), o domínio sobre as perversões no decorrer do século XIX permaneceu, em grande parte, restrito à legislação, sendo o interesse da medicina dedicado a esse tipo de fenômeno bastante tardio e indireto. Os médicos só se ocupavam delas a pedido dos magistrados, os quais, apenas vez por outra, admitiam que formulassem uma opinião sobre o assunto. Nessa passagem do domínio sobre as perversões da moral religiosa para a ciência médica, uma figura destacou-se entre as demais: o homossexual.

\section{Sodomitas, pederastas, uranistas e invertidos}

"Fornicação não natural, seja entre pessoas do sexo masculino ou de humanos com animais, deve ser punida com prisão; a sentença de perda dos direitos civis também pode ser aplicada": este é o infame parágrafo 175 do Código Penal prussiano, adotado em 1871, logo após a unificação do Império Alemão. A sodomia entre homens era severamente punida — medida que foi estendida a todos os Estados que compunham o Império Alemão, inclusive àqueles que já não puniam a homossexualidade. Note-se ainda que a legislação prussiana não punia qualquer aspecto da homossexualidade masculina, mas condenava precisamente a fornicação, isto é, o coito anal, e a verdade sobre o ato só poderia ser estabelecida através da confissão de um dos parceiros (Lantéri-Laura, 1979/1994). 
Notemos que os procedimentos regulamentados da confissão do sexo, da sexualidade e dos prazeres sexuais se imiscuem irrevogavelmente nos interstícios das instituições de poder, seguindo técnicas muito refinadas que põem a sexualidade do sujeito sob escrutínio (Foucault, 1979/2010). A confissão vem justamente para extrair uma verdade sobre o sujeito, com o intuito de autenticar um ato de expressão da sexualidade como ato de verdade. Este mecanismo que liga o sexo e sua enunciação à verdade de si mesmo estendeu seus efeitos das instituições religiosas para diversas outras, aí incluindo a justiça, a pedagogia, as relações familiares e, sobretudo, a medicina (Benevides, 2013).

A confissão difundiu amplamente seus efeitos: na justiça, na medicina, na pedagogia, nas relações familiares, nas relações amorosas, na esfera mais cotidiana e nos ritos mais solenes; confessam-se os crimes, os pecados, os pensamentos e os desejos, confessam-se passado e sonhos, confessa-se a infância; confessam-se as próprias doenças e misérias; emprega-se a maior exatidão para dizer o mais difícil de ser dito; confessa-se em público, em particular, aos pais, aos educadores, ao médico, àqueles a quem se ama; fazem-se a si próprios, no prazer e na dor, confissões impossíveis de confiar a outrem, a confessar. Quando a confissão não é espontânea ou imposta por algum imperativo interior, é extorquida; desencavam-na na alma ou arrancam-na no corpo. (Foucault, 1976/1988, pp. 67-8)

Nessa transição entre o fim do século XVIII e o início do século XIX, vê-se surgir, dentre o que era tido como perversão, a personagem do homossexual, verdadeiro representante desse período. Ao analisar através de quais fenômenos a medicina positivista da segunda metade do século XIX passou a se interessar pelo problema das perversões, Lantéri-Laura (1979/1994) afirma que ela o fez através de um estudo detalhado da homossexualidade, o qual precedeu e influenciou diretamente as sínteses gerais comandadas por Krafft-Ebing e Havelock Ellis. Tais pesquisas desenvolveram-se, sobretudo, nos países de língua germânica e visavam, por um lado, conhecer melhor o que estava em questão nos fenômenos em causa e, por outro, modificar uma legislação penal que continuava uniformemente repressiva. Nesse sentido, os primeiros estudos médicos sobre a homossexualidade tenderam a concebê-la como um fenômeno que nada tinha de monstruoso, mas representava uma variedade de acesso ao gozo.

O Código Penal francês da época, inclusive, parecia bastante liberal no que concernia aos crimes e delitos, bem como em suas punições, que tinham a sexualidade como tema principal: "o legislador só pretendia punir, em 
matéria de comportamentos sexuais, o escândalo público do ultraje aos bons costumes e o atentado ao pudor; nessa segunda eventualidade, só existia falta em função de dois elementos: a idade e o consentimento" (Lantéri-Laura, 1979/1994, p. 15). Ou seja, a letra da Lei punia o escândalo público, protegia os menores de idade e condenava a violência cometida contra um adulto sem seu consentimento. O legislador burguês não tinha interesse algum em se intrometer na sexualidade dos adultos, nem preocupações quanto às diversas formas de se chegar ao orgasmo.

Ademais, nesses casos, no início do século XIX, a medicina tinha menos um papel de sustentar um discurso psicopatológico sobre o réu do que descrever ao tribunal os danos sofridos pela vítima. $\mathrm{O}$ discurso médico acerca dos propósitos dos comportamentos sexuais se limitava a alegar que múltiplas condutas sexuais eram nada mais que variedades da alienação mental, que giravam em torno da categoria das monomanias instintivas, definidas por Esquirol. Por essa categorização, vemos o esforço dos peritos médicos de passar do estudo dos danos na vítima para uma análise clínica do sujeito acusado. A progressiva captura desses casos pela medicina representou, portanto, importante mudança na ótica do julgamento: não se tratava tanto de punir tais atos, mas de tratá-los para prevenir sua recidiva; não se trataria do caráter exemplar do castigo, mas da eficácia da terapêutica.

É como uma das "aberrações sexuais", possuidora da luxúria em seu mais evidente estado, que a figura do sodomita se destaca na história da sexualidade. De acordo com Marchand (2011), até o final do século XVIII, a moral cristã regulava as práticas sexuais com tanto peso quanto o Direito, e os tribunais eclesiásticos estavam encarregados de julgar os atos sodomitas. Esses eram considerados um pecado pelo qual a pena de morte (em geral, a pira funerária) poderia ser imposta.

Salienta Heckma (1991) que o movimento de descriminalização da sodomia na Europa teve início a partir da crítica dos filósofos iluministas à severidade da penalidade que lhe era conferida, em especial nos estados prussianos. No entanto, tal descriminalização implicou considerável mudança de ótica acerca do fato: se até então os manuais de medicina forense se dedicavam a estudar as consequências dos atos de sodomia, a partir de 1800 o foco passa a recair sobre suas causas e sobre o caráter dos sodomitas. Os peritos progressivamente não mais examinavam o corpo das "vítimas" do ato, mas passaram a analisar o estado mental do próprio autor.

É nessa passagem do domínio religioso-moral para o domínio positivista da medicina que começam a despontar algumas produções teórico-clínicas, 
em especial no campo da medicina forense. De acordo com Heckma (1991), este é o caso, por exemplo, do médico vienense Heinrich Kaan, que, em 1844, publicou uma tese afirmando que a prática masturbatória levaria a todas as outras perversões conhecidas pela medicina forense e, ulteriormente, à insanidade; do alienista francês Claude-François Michéa, o qual, em 1849, pela primeira vez, articulou a homossexualidade a uma teoria biológico-fisicalista, afirmando que os homossexuais masculinos sofreriam de uma disfunção fisiológica, pois possuiriam um órgão feminino em seu corpo; e do médico forense alemão Johann Ludwig Casper - que, por sua vez, expôs as qualidades femininas da personalidade dos pederastas, chamando-os de "hermafroditas da mente". Sublinha ainda Heckma (1991) que foi, no entanto, o jurista alemão Karl Heinrich Ulrichs quem desenvolveu um constructo teórico de reconhecida importância, na época, para os estudos da homossexualidade. Em 1869 ele cunhou o termo "uranismo", que viria designar "uma alma de mulher em um corpo masculino", espécie de "hermafroditismo psíquico" inato. Esse tipo particular de homossexualidade masculina não podia se tratar de algo patológico, mas de uma disposição singular da natureza (congênita), na qual nada se podia modificar. Não 694 sendo os uranistas doentes, seriam apenas uma variedade da espécie humana.

Ao situar o uranismo fora do campo patológico, Ulrichs distinguiu-o da doença mental e da devassidão, reclamando seu direito à não repressão penal. O uranismo seria um modo particular de satisfação sexual, derivado de um dado natural e, portanto, relacionado com a natureza, não contrário a ela. A tese do referido autor, destaca Heckma (1991), visava criticar a criminalização da homossexualidade na Alemanha: uma vez que se tratava de algo inato, e não adquirido ou aprendido, criminalizar a homossexualidade seria um despropósito. Sua mensagem foi recebida positivamente pela comunidade médica europeia, que acabou por concluir que a sodomia não era prejudicial.

Apesar da pressão contrária de grupos cristãos que desejavam a manutenção do estatuto criminoso da "fornicação não natural", a teoria de Ulrichs alcançou sucesso expressivo nos círculos médicos. Muitos psiquiatras berlinenses endossaram-na, conquanto a levaram em outra direção. O psiquiatra alemão Karl Friedrich Otto Westphal, em 1870, publicou um artigo em que descrevia o que chamou de "sensibilidade sexual inversa", isto é, um modo de experimentar o sexual de maneira oposta ao habitual: estavam então batizados os "invertidos". A "sensibilidade sexual inversa" fazia referência à heterossexualidade, a qual permanecia considerada como a forma "normal" da sexualidade (Heckma, 1991). 
De acordo com a leitura de Lantéri-Laura (1979/1994), Westphal considerava a inversão sexual condição psicopatológica que deveria ser objeto de estudo psiquiátrico. Da mesma forma como Ulrichs, ele acreditava no caráter congênito de tais casos, sem insistir em uma eventual hereditariedade. Ambos consideravam a inversão sexual fazendo parte da própria natureza, de modo que a expressão moral-religiosa de "costumes contrários à natureza" não tinha nenhuma significação científica.

Após Westphal, o trabalho do psiquiatra alemão Albert Moll foi o que, sem dúvida, representou a investigação clínica mais exaustiva sobre a homossexualidade. Ao se dedicar ao estudo das "perversões do instinto genital", ele interrogou-se sobre a etiologia da inversão, também afirmando seu caráter congênito, mas admitindo a importância de certas causas fortuitas — como o fato de o homem ter visto cenas sexuais na infância, ou passar uma vida reclusa e sem mulheres.

Para Moll, a explicação para a "inversão do instinto genital" não se encontraria nos órgãos genitais propriamente ditos (pois estes funcionam normalmente nesses casos), mas sim no processamento mental, feito pelo sistema nervoso central, dos sentidos genitais. A sexualidade seria, portanto, uma função fisiológica dentre outras, cujo processamento mental, nos invertidos, encontrar-se-ia desviado - em vez de a representação mental da mulher excitar o sentido genital do homem, nos invertidos (masculinos) a excitação seria provocada pela ideia de homem. Além disso, a ligação da sexualidade às funções reprodutivas era, na espécie humana, algo puramente teleológico que a ciência não poderia corroborar e que era incapaz de estabelecer as fronteiras entre o normal e o patológico (Heckma, 1991).

Dessa forma, tanto Ulrichs e Westphal quanto Moll desenvolveram suas primeiras pesquisas no sentido de corrigir a legislação penal, ao mostrar que a homossexualidade não era algo penalizável, mas uma das variações para se chegar ao orgasmo, sem que qualquer autoridade jurídica tivesse qualquer ingerência sobre o assunto.

O que se vê, contudo, nesse movimento de transição, é como a homossexualidade - e as perversões de um modo geral — progressivamente sai do domínio da medicina forense e do discurso jurídico para entrar de vez no discurso médico-psiquiátrico, passando de crime a psicopatologia. $\mathrm{O}$ sujeito homossexual surgiu como um dos primeiros "tipos" a serem investigados detalhadamente pelo saber médico oitocentista, em estudos que precederam as grandes sínteses do fim do século XIX, mas o movimento não ficou restrito a ele. A partir do último terço do século, uma série de "aberrações sexuais" 
tornou-se alvo de estudos científicos realizados pela psiquiatria, passando a estudar as variações dos comportamentos sexuais, as quais se transformariam pouco a pouco em capítulos específicos dos grandes tratados de classificação das perversões.

\section{Os grandes compêndios das aberrações sexuais}

$\mathrm{Na}$ segunda metade do século XIX, a emergência da psicopatologia sexual a partir do discurso médico-psiquiátrico promoveu verdadeira revolução científica no que concerne à sexualidade e às práticas sexuais. $\mathrm{O}$ modelo da medicina forense - cujo interesse centrava-se nas consequências físicas das práticas sexuais - começava a caducar e a ser abandonado. No período entre 1880 e 1895, a psicopatologia sexual era uma ciência em desenvolvimento, cuja atenção se fixa na questão das determinações dos indivíduos com desejos sexuais "fora do normal" serem de natureza fisiológica ou psicológica (Heckma, 1991).

Surge um interesse crescente nas "aberrações sexuais" com o objetivo de classificá-las, descrevê-las e determinar suas causas. Essa classificação, a princípio, deu-se de forma desordenada, uma vez que não havia consenso acerca da nomenclatura dos fenômenos em questão e, muito menos, de sua determinação causal. Até que a Psychopathia sexualis de Richard von Krafft-Ebing fosse publicada em 1886, representando a tentativa mais conhecida no sentido de unificar o discurso médico-psiquiátrico a respeito das "aberrações sexuais", uma série de tentativas independentes despontaram na diligência de adequar o conhecimento psicopatológico aos princípios do modelo positivista da ciência.

Destaca Pacheco (2003) que a medicina no século XIX comportava uma preocupação ostensiva de diferenciar-se da filosofia, da religião e também da psicologia, cujos objetos de conhecimento transcendiam a matéria, dirigindo-se ao mundo espiritual. Ela buscava aproximar-se das ciências naturais, consolidando seu saber e sua terapêutica em critérios (supostamente) objetivos. Vê-se então progressivamente se desenvolver a concepção das anomalias mentais como "decorrência de distúrbios orgânicos provindos de disfunções de estruturas orgânicas, ou ainda de lesões anatômicas ou funcionais do encéfalo, e que se refletiam no comportamento sob a forma de sintomas" (p. 153). 


\section{HISTÓRIA DA PSICANÁLISE}

Durante boa parte do século XIX, contudo, a concepção psiquiátrica da perversão permaneceu ainda fortemente atrelada a ideais morais, encontrando na noção de degenerescência um campo prolífico de desenvolvimento (Pirlot \& Pedinielli, 2013).

O Traité des Dégénérescences, de Benedict-Augustin Morel, publicado em 1857, expõe uma teoria da hereditariedade dos transtornos mentais que teria grande influência no pensamento psiquiátrico até o início do século XX. Segundo sua proposição, fortemente impregnada de uma perspectiva religiosa católica, o homem teria sido criado perfeito, por Deus. A degeneração, correlativa do pecado original, consistiria na transmissão à descendência das taras, vícios e traços mórbidos adquiridos pelos antecessores. [...] Em decorrência dessa teoria, muitos projetos de intervenção social de cunho higienista foram desenvolvidos de modo a impedir a propagação da degeneração da raça. (Pereira, 2008, p. 490)

Peixoto Jr. (1999) chama atenção para o fato de que os degenerados de Morel eram descritos como sujeitos intelectualmente degradados, rebaixados como seres de razão - o que era inaceitável para os ideais iluministas vigentes. Sua irracionalidade misturava-se com uma "a-moralidade", e toda sua teoria acabava por reescrever tradições morais seculares sob a forma de um vocabulário científico. Além disso, outro ponto fundamental da teoria da degenerescência dizia respeito à articulação entre a hereditariedade biológica e a moral.

Na primeira metade do século, a articulação entre os traços transmitidos pela herança biológica, de um lado, e os fatores acidentais, biográficos, morais e psicológicos, de outro, era feita de maneira confusa e inespecífica, de modo que a publicação de Morel veio oferecer uma mudança significativa acerca das formas de se compreender como o herdado participaria da determinação das perversões sexuais. Sua teoria desenvolve-se a partir da concepção de que "a herança que se transmite através das gerações não se restringe ao plano biológico, mas inclui dimensões morais e de comportamentos - virtuosos ou viciados" (Pereira, 2008, p. 492). A potencialidade explicativa da degenerescência repousa sobre a ideia de que todos os traços mórbidos ou aberrantes de uma pessoa poderiam ser justificados a partir da conduta de um antepassado, de alguém da família. O caráter metafísico de sua teoria foi duramente questionado posteriormente, mas não deixou de exercer bastante influência nas concepções psicopatológicas do fim do século.

Como sustenta Foucault (1976/1988), o conjunto perversão-hereditariedade-degenerescência passa a constituir o núcleo sólido das novas tecnologias 
do sexo. Define-se, então, “um passado, uma história, uma infância, um caráter, uma forma de vida; também é morfologia, com uma anatomia indiscreta e, talvez, uma fisiologia misteriosa. Nada daquilo que ele é, no fim das contas, escapa à sua sexualidade" (p. 50). Com isso, atesta-se agora mais do que nunca como, progressivamente, a sexualidade adquire peso fundamental na concepção dos indivíduos, de sua "natureza". Os psiquiatras do século XIX entomologizaram as diferentes espécies de perversos, constituindo um grande "herbário" dos prazeres do sexo, classificando-os e descrevendo-os a partir do discurso da ciência. E, mais importante, a sexualidade passa a ser incorporada, inserida nos corpos, nas condutas dos indivíduos, tornando-se princípio de classificação e inteligibilidade.

A moral moreliana perde espaço para o organicismo científico. Nesse momento surgem os grandes compêndios dos transtornos psiquiátricos Kaan, Krafft-Ebing, Moll e Ellis são representantes desse movimento de psiquiatrização das "perversões", que viria a tomar o lugar da superada categoria moral da degenerescência. Krafft-Ebing foi um dos principais autores que procurou organizar o "herbário" das sexualidades, e sua obra mais conhecida, Psychopatia sexualis, publicada originalmente em 1886, alcançou enorme sucesso entre os psiquiatras de sua época. De acordo com Heckma (1991), de 1886 a 1894, uma versão significativamente aumentada do livro aparecia a cada ano, fazendo com que ele crescesse de 110 para 440 páginas. Em sua décima-sétima edição, revista por Albert Moll, ele já contava com 838 páginas.

Ao se percorrer o tratado clínico de Krafft-Ebing, encontra-se na homossexualidade o centro organizador de sua argumentação sobre as perversões - agora não mais entendida como crime, mas sim como categoria psicopatológica; e, para além dela, havia a descrição do sadismo, do masoquismo, do fetichismo, do exibicionismo e da zoofilia.

No entanto, a unificação do discurso médico-psiquiátrico ainda era uma questão. A clínica permanecia apoiada em uma diversidade — empiricamente legítima, mas, doutrinariamente excessivamente vasta. A obra "Das anomalias, das aberrações e das perversões sexuais", publicada em 1885 pelo o psiquiatra francês Valentin Magnan propõe uma maneira de reunir a variedade dos comportamentos perversos em uma interpretação neurofisiológica, e sua síntese constitui um dos mais exatos testemunhos da teoria positivista das perversões do fim do século XIX. Magnan criticava o método clínico de sua época, afirmando que ele permanecia no nível das aparências, necessitando de fundamentos anatomofisiológicos para conformar-se aos preceitos 
positivistas da ciência (Lantéri-Laura, 1979/1994; Peixoto Jr., 1999; Pirlot \& Pedinielli, 2013).

Segundo Magnan, os fenômenos perversos só poderiam ser decifrados a partir da compreensão anatomofisiológica dos distúrbios no funcionamento hierarquizado do sistema nervoso central. Ele propunha um modelo anatômico organizado do comportamento sexual normal e, a partir dele, formulava as alterações específicas que embasariam o entendimento das perversões. A sexualidade normal corresponderia a um funcionamento equilibrado das relações entre o arco reflexo espinhal e os centros corticais - de modo que as perversões estariam relacionadas às disfunções dessas relações. Com isso, Magnan faz passar a compreensão psiquiátrica das perversões de uma interminável enumeração de casos para uma explicação elementar fisicalista do sistema nervoso central e de suas localizações, deslocando o interesse das condutas perversas para a estrutura patológica do paciente.

As perversões sexuais puderam então ser compreendidas como condutas que permitiam atingir o orgasmo com um funcionamento neurofisiológico incomum e desarmônico [...]. Os perversos não o eram nem porque fizessem amor diferentemente da média das pessoas, nem porque suas condutas não levassem à fecundação, mas porque seus comportamentos correspondiam a uma desestruturação da ordem do sistema nervoso central. Havia uma raiz de sua pertinência ao domínio do patológico. (Lantéri-Laura, 1979/1994, pp. 55-6; grifos do autor)

Apesar de bem aceitas a princípio, as teses de Krafft-Ebing e de Magnan provocam intensas discussões nos anos seguintes, em especial no que concerne à exclusividade fisicalista própria às suas teorias. Mostra Peixoto Jr. (1999) que um ano após a publicação da tese de Magnan, em 1886, Alfred Binet propôs a primeira explicação psicológica das perversões, dando ênfase a eventos fortuitos vividos geralmente na infância que, durante a juventude, provocariam forte associação de ideias levando a doenças amorosas e a atos perversos. A crítica de Binet abre caminho para autores como o psiquiatra alemão Albert von Schrenck-Notzing sustentarem a utilização da sugestão hipnótica no tratamento das perversões para desfazer a associação patológica e substituí-la por uma normal

Segundo Sigusch (2012) e Heckma (1991), contudo, foi com a publicação de "Estudos sobre a libido sexual" pelo sexólogo alemão Albert Moll em 1897 que se viu desenvolver pela primeira vez um trabalho científico substancial a respeito de uma teoria geral da sexualidade. De acordo com esse autor, ambos os impulsos sexuais — normal e perverso — eram uma 
combinação de dois elementos: um impulso de descarga, que se refere à necessidade orgânica de liberar secreção; e um impulso de "contrectação", de relacionamento, poder-se-ia dizer, que se refere ao lado social do impulso sexual e que diz respeito à atração pelo outro. Partindo daí, uma das decisivas contribuições de Moll foi desarticular a sexualidade da reprodução, ao afirmar que a reprodução nada mais seria do que um resultado fortuito de certos atos sexuais, mas esses certamente não seriam restritos a ela.

\section{Considerações finais}

Enfim, o que se vê delinear no final do século XIX é uma descrição científica da sexualidade e das práticas sexuais, baseada em um discurso positivista ao qual os trabalhos posteriores não acrescentariam nada muito distinto. Essa descrição culminou na súmula de Ellis, fornecendo uma nomenclatura específica que permaneceu vigente por muitos anos à frente. É notável como encontramos até hoje, tanto no Manual Diagnóstico e Estatístico de Transtornos Mentais (DSM), organizado pela Associação de Psiquiatria Americana (APA), quanto na Classificação Internacional de Doenças (CID), organizada pela Organização Mundial de Saúde (OMS), os ecos desses compêndios psiquiátricos do final do século XIX. Se, atualmente, as perversões assumem, de modo geral, a designação de "transtornos parafílicos", a origem dessa está diretamente vinculada às súmulas de Krafft-Ebing e Ellis (Abdo, 2016).

Além disso, vê-se fixar uma linguagem conceitual com ressonâncias no discurso freudiano sobre a sexualidade e, especificamente, sobre as perversões - linguagem da qual Freud irá se aproximar, em alguns momentos, mas justamente para dela profundamente se desviar. Freud herdou certo modelo de raciocínio positivista da psiquiatria da sua época, mas promoveu profunda ruptura em relação a ele, o que indica diferenças substanciais básicas entre o discurso psicanalítico e o médico-científico contemporâneo a ele (Peixoto Jr., 1999). De fato, no que concerne à epistemologia, mesmo quando uma teoria é radicalmente inovadora, ela aparece marcada por determinado campo de conceitos existente na época, e é a partir desses conceitos disponíveis que se expressará a novidade.

Como salienta Cirino (2007), retomando a história da sexualidade a partir de Foucault, é pelo viés desse objeto, inventado e nomeado, "dispositivo de sexualidade" — no qual "falar de sexo" se destaca como traço 


\section{HISTÓRIA DA PSICANÁLISE}

pertinente - que se pode situar o aparecimento da psicanálise e o corte epistemológico, essencialmente transgressor, que ela veio produzir nas formas de se compreender as perversões e os sujeitos ditos perversos. É por Freud ter efetuado uma passagem essencial, difícil e fundamentalmente inovadora, que o caráter revolucionário de sua obra permitiu que ele desempenhasse papel essencial na evolução dos discursos sobre a sexualidade e, consequentemente, sobre as perversões.

\section{Referências}

Abdo, C. H. N. (2016). A evolução do conceito de parafilias. Debates em Psiquiatria, 4, 36-41.

Benevides, P. S. (2013). Verdade, liberdade e sexualidade em A vontade de saber. Política \& Trabalho - Revista de Ciências Sociais, 38, 233-250.

Birman, J. (1999). A perversão no social. In C. A. Peixoto Jr. Metamorfoses entre o sexual e o social: uma leitura da teoria psicanalítica sobre a perversão. Rio de Janeiro, RJ: Civilização Brasileira.

Cirino, O. (2007). O desejo, os corpos e os prazeres em Michel Foucault. Mental, 8, 77-89.

Foucault, M. (1988). História da sexualidade I: A vontade de saber. Rio de Janeiro, RJ: Graal. (Trabalho original publicado em 1976).

Foucault, M. (2010). Sobre a história da sexualidade. In M. Foucault. Microfísica do poder. Rio de Janeiro, RJ: Graal. (Trabalho original publicado em 1979).

Freud, S. (1996a). A etiologia da histeria. In Edição Standard Brasileira das Obras Psicológicas Completas de Sigmund Freud (Vol. 3, pp. 185-215). Rio de Janeiro, RJ: Imago. (Trabalho original publicado em 1896).

Freud, S. (1996b). A interpretação dos sonhos. In Edição Standard Brasileira das Obras Psicológicas Completas de Sigmund Freud (Vol. 4, pp. 13-363). Rio de Janeiro, RJ: Imago. (Trabalho original publicado em 1900).

Freud, S. (1996c). Três ensaios sobre a teoria da sexualidade. In Edição Standard Brasileira das Obras Psicológicas Completas de Sigmund Freud (Vol. 7, pp. 117231). Rio de Janeiro, RJ: Imago. (Trabalho original publicado em 1905)

Freud, S. (1996d). Sobre o narcisismo: uma introdução. In Edição Standard Brasileira das Obras Psicológicas Completas de Sigmund Freud (Vol. 14, pp. 75-108). Rio de Janeiro, RJ: Imago. (Trabalho original publicado em 1914).

Freud, S. (1996e). O mal-estar na civilização. In Edição Standard Brasileira das 
Obras Psicológicas Completas de Sigmund Freud (Vol. 21, pp. 65-148). Rio de Janeiro, RJ: Imago. (Trabalho original escrito em 1929 e publicado em $1930[1920])$.

Freud, S. (1996f). A divisão do ego no processo de defesa. In Moisés e o monoteísmo, esboço de psicanálise e outros trabalhos (1937-1939) - Edição Standard Brasileira das Obras Psicológicas Completas de Sigmund Freud (Vol. 23, pp. 289-296). Rio de Janeiro, RJ: Imago. (Trabalho original escrito em 1938 e publicado em 1940).

Gratton, E. (2016). Discours psychanalytiques à propôs de la sexualité transgression, perversion et subversion. Dialogue, 212, 11-24.

Heckma, G. (1991). A history of sexology: social and historical aspects of sexuality. In G. Heckma. From Sappho to De Sade: moments in the history of sexuality. New York, NY: Routledge.

Lantéri-Laura, G. (1994). Leitura das perversões: história de sua apropriação médica. Rio de Janeiro, RJ: Jorge Zahar. (Trabalho original publicado em 1979).

Marchand, G. (2011). Les dessous de la perversion. Sciences Humaines, 130.

Pacheco, M. V. P. C. (2003, junho). Esquirol e o surgimento da psiquiatria contemporânea. Revista Latinoamericana de Psicopatologia Fundamental, 6(2), 152-157.

Peixoto Jr., C. A. (1999). Metamorfoses entre o sexual e o social: uma leitura da teoria psicanalítica sobre a perversão. Rio de Janeiro, RJ: Civilização Brasileira.

Pereira, M. E. C. (2008, setembro). Morel e a questão da degenerescência. Revista Latinoamericana de Psicopatologia Fundamental, 11(3), 490-496.

Pirlot, G., \& Pedinielli, J.-L. (2013). Les perversions sexuelles et narcissiques. Paris, FR: Armand Colin.

Roudinesco, E. (2008). A parte obscura de nós mesmos: uma história dos perversos. Rio de Janeiro, RJ: Zahar. (Trabalho original publicado em 2007).

Santo Agostinho (2012). A cidade de Deus. Petrópolis, RJ: Vozes. (Trabalho original publicado em 1989).

Santos, A. B. R. \& Ceccarelli, P. R. (2010). Psicanálise e moral sexual. Reverso, 59, 23-30.

Sigusch, V. (2012). The sexologist Albert Moll - between Sigmund Freud and Magnus Hirschfeld. Med. Hist., 56(2), 184-200.

Trese, L. J. (1999). O sexto e o nono mandamentos. In A fé explicada. São Paulo, SP: Quadrante. 


\section{HISTÓRIA DA PSICANÁLISE}

\section{Resumos}

(Sin, crime and pathology: discursive productions on perversion)

Based on the genealogical and epistemological analyzes proposed by Foucault and Lanteri-Laura, we aim to discern which are the main discursive lines that constituted the knowledge around perversion, producing a so-called perverse subject. It emerges in a fundamental way from this reading how the idea of transgression of limits accompanies the history of the perverse: whether the moral limit imposed by divine authority, whether the legal limit determined by criminal law, or the normal limit defined by medicine, perversion always points towards the transgressive excess. Such readings constitute the epistemological ground on which Freud relies to develop the conception of a metapsychology whose central axis is sexuality. The Freudian discourse subverts the status of perversion by affirming it as an inescapable dimension of sexuality and of the constitution of human subjectivity.

Key words: Perversion, sexuality, transgression, psychoanalysis

(Péché, crime et pathologie: productions discursives sur la perversion)

Sur la base des analyses généalogique et épistémologique proposées par 703 Foucault et Lanteri-Laura, notre objectif principal est de discerner quelles sont les principales lignes discursives qui constituaient les connaissances autour de la perversion, produisant un sujet dit pervers. Il ressort de manière fondamentale de cette lecture comment l'idée de transgression des limites accompagne l'histoire du pervers : soit la limite morale imposée par l'autorité divine, soit la limite légale déterminée par le droit pénal, ou la limite normale définie par la médecine, la perversion pointe toujours dans la direction de l'excès transgressif. Ces lectures constituent le terrain épistémologique sur lequel Freud s'appuie pour la conception d'une métapsychologie dont l'axe central est la sexualité. Le discours freudien subvertit le statut de perversion en l'affirmant comme une dimension incontournable de la sexualité et de la constitution de la subjectivité humaine.

Mots clés: Perversion, sexualité, transgression, psychanalyse

(Pecado, crimen y patología: producciones discursivas acerca de la perversión)

Basado en los análisis genealógico y epistemológico propuestos por Foucault y por Lanteri-Laura, nuestro principal objetivo es discernir cuáles son las principales líneas discursivas que constituyeron el conocimiento en materia de perversión, produciendo un sujeto denominado perverso. De esta lectura surge de manera fundamental 
la idea de que la transgresión de los límites acompaña la historia de lo perverso: ya sea el límite moral impuesto por la autoridad divina, el límite legal determinado por el derecho penal o el límite normal definido por la medicina, la perversión siempre señala el exceso transgresor. Tales lecturas constituyen el fundamento epistemológico en el que Freud se basa para la concepción de una metapsicología cuyo eje central es la sexualidad. El discurso freudiano trastorna el estatuto de la perversión al afirmarla como una dimensión ineludible de la sexualidad y de la constitución de la subjetividad humana.

Palabras clave: Perversión, sexualidad, transgresión, psicoanálisis

Citação/Citation: Vale, A. L. A. do, \& Cardoso, M. R.. (2021, dez.). Pecado, crime e patologia: produções discursivas acerca da perversão. Revista Latinoamericana de Psicopatologia Fundamental, 24(4), 682-705. http://dx.doi.org/10.1590/1415-4714.2021v24n4p682.10

Editora/Editor: Prof. Dr. Marco Antonio Coutinho Jorge

Submetido/Submitted: 29.12.2020 / 12.29.2020 Aceito/Accepted: 11.3.2021 / 3.11.2021

Copyright: (C) 2009 Associação Universitária de Pesquisa em Psicopatologia Fundamental/ University Association for Research in Fundamental Psychopathology. Este é um artigo de livre acesso, que permite uso irrestrito, distribuição e reprodução em qualquer meio, desde que o autor e a fonte sejam citados / This is an open-access article, which permits unrestricted use, distribution, and reproduction in any medium, provided the original authors and sources are credited.

Financiamento/Funding: Este trabalho recebeu apoio da Coordenação de Aperfeiçoamento de Pessoal de Nivel Superior - Capes (Bolsa de Doutorado - Programa de Demanda Social e Bolsa de Doutorado Saduíche no Exterior - Edital n.19/2016) (Brasília, DF, Br.), e Conselho Nacional de Desenvolvimento Científico e Tecnológico - CNPq (Brasília, DF, Br) / This work is supported by Coordenação de Aperfeiçoamento de Pessoal de Nivel Superior-Capes (Bolsa de Doutorado - Programa de Demanda Social e Bolsa de Doutorado Saduíche no Exterior Edital n.19/2016) (Brasília, DF, Br.), and Conselho Nacional de Desenvolvimento Científico e Tecnológico - CNPq (Brasília, DF, Br).

Conflito de interesses/Conflict of interest: Os autores declaram que não há conflito de interesses. / The authors declare that there is no conflict of interest.

André Luiz Alexandre do Vale

Psicólogo; Doutor em Teoria Psicanalítica - Universidade Federal do Rio de Janeiro - UFRJ

(Rio de Janeiro, RJ, Br).

Rua São Salvador, 14/402

22231-130 Rio de Janeiro, RJ, Br.

alavale88@gmail.com

https://orcid.org/0000-0003-4906-346X 


\section{HISTÓRIA DA PSICANÁLISE}

Marta Rezende Cardoso

Psicanalista; Doutora em Psicopatologia Fundamental e Psicanálise - Universidade de Paris Diderot (Paris, França); Professora Titular da Universidade Federal do Rio de Janeiro -UFRJ (Programa de Pós-Graduação em Teoria Psicanalítica e Departamento de Psicologia Clínica) (Rio de Janeiro, RJ. Br); Membro da Associação Universitária de Pesquisa em Psicopatologia Fundamental (São Paulo, SP, Br); Pesquisadora do CNPq (Bolsista de Produtividade em Pesquisa) (Brasília, DF, Br).

Rua Gustavo Sampaio, 710/1805

22010-010, Rio de Janeiro, RJ, Br.

rezendecardoso@gmail.com

https://orcid.org/org/0000-0003-1104-9830

This is an open-access article, which permits unrestricted use, distribution, and reproduction in any medium for non-commercial purposes provided the original authors and sources are credited. 